Original Paper http://ajol.info/index.php/ijbcs http://indexmedicus.afro.who.int

\title{
Malaria prevalence and In vitro susceptibility of Plasmodium falciparum isolates to selected antimalarial agents in Bauchi, Nigeria
}

\author{
Awute David ATANG, Jonathan Yusuf AZI, Faizah Oseze SANI, \\ Rukayat Avosuahi OYI and Joseph Olorunmola EHINMIDU*
Department of Pharmaceutics and Pharmaceutical Microbiology, Ahamadu Bello University, Zaria, Kaduna State, Nigeria.
"Corresponding author; E-mail: ehinmidu1953@yahoo.com; Tel: +2348037033204

\begin{abstract}
Malaria has been reported to be a high bio burden disease in sub-Sahara African Countries. About $50 \%$ has been associated with at least one episode of malaria while children were reported with two or four episodes. This study reports the prevalence of malaria and susceptibility pattern of Plasmodium falciparum isolates from patients visiting Specialist Hospital Bauchi, Nigeria to reportedly prescribed antimalarial agents in Bauchi. Information on malaria patients and antimalarial drugs prescribed to the patients were collected and documented. In vitro antimalarial susceptibility assay was carried out using in vitro micro test. The average malaria prevalence of $22.78 \%$ was reported from January 2015 to December 2017. The survey also revealed that more female patients recorded the highest incidence of malaria to male patients. Four antimalarial drugs were reported to be routinely prescribed in the Health facility from 2015 to 2017: viz ACT (Artemisnin based Combined Therapies) $88.06 \%$; Artesunate 10.29\%; while Sulphadoxine-Pyrimethamine and Quinine were $3.96 \%$ and $0.99 \%$ respectively. The pattern of Plasmodium falciparum isolates resistant to test antimalarial drugs were Chloroquine 27.06\% > (Artemether-Lumefantrine) $18.82 \%>$ Artemether $14.12 \%>$ Quinine $4.71 \%$. With the increasing pressure on the usage or prescription of ACTs in malaria treatment, the development of high level of resistance to ACTs is now a high probability.
\end{abstract}

(C) 2019 International Formulae Group. All rights reserved.

Keywords: Malaria, inhibitory concentration, assay, resistance, antimalarial.

\section{INTRODUCTION}

Malaria is one of the leading causes of death in the world especially in the third world countries e.g Africa, East Asia and South America. Malaria is a blood disease caused by a parasitic protozoan of genus Plasmodium and mainly transmitted to humans through bite from an infected female Anopheles Mosquitoes (Wande and Babatunde, 2018). Global cases of malaria have reached 219 million high with about
435000 deaths recorded in 2017, particularly in sub-Saharan Africa (WHO, 2018). Nigeria has the highest burden of malaria globally, accounting to up to $25 \%$ of the global cases and $19 \%$ of the global deaths WHO (2018) while an estimated $97 \%$ of the total population of Nigeria was reported at risk of Malaria infection (WHO, 2014). Malaria was reported to be responsible for $60 \%$ outpatient visits in various health centers across Nigeria and has 
the greatest impact among children under five, accounting to $30 \%$ child mortality (WHO, 2014). In 2004, Artemether-Lumefantrine (AL) or Artesunate + Amodiaquine $(\mathrm{AS}+\mathrm{AQ})$ was adopted as first line of treatment for uncomplicated malaria by Nigerian Federal Ministry of Health in 2005 due to Chloroquine and SulphadoxinePyrimethamine treatment failures (WHO, 2018).

Recent studies have shown that Artemisinin-Lumefantrine combination was the most prescribed antimalarial agent in line with the Federal Ministry of Health treatment policy of 2005, aimed to fight the fast encroachment of resistance (Builders et al., 2014). This policy guideline was developed due to reduced susceptibility of Plasmodium falciparum to Chloroquine and SulphadoxinePyrimethamine that necessitated the review of antimalarial drug policy in favor of Artemisinin Combination Therapy (ACT) as the first line of treatment for uncomplicated Malaria (Gbotosho et al., 2009).

Antimalarial drug resistance has become one of the greatest problems facing malaria control today. Control and elimination of malaria has been very difficult due to the observed ability of Plasmodium falciparum to easily develop resistance to effective administered Chemoprophylatic and Chemotherapeutic agents (Peletri el al., 2012). In vitro antimalarial investigations over the years have revealed the presence of resistance to commonly prescribed antimalarial agents which has continued to worsen the burden of the disease.

Before the discovery of Artemisinin, Chloroquine has been reported to play an important role in the treatment of malaria due to its effectiveness, availability, safety and reduced cost supporting regions of high cases of the disease (Laxminarayan and Gelband, 2009). Over the years, Chloroquine resistant $P$. falciparum developed due to the huge burden on the drug and later spread from South-East Asia to Africa regions (Peletri et al., 2012; Shujatullah et al., 2012).

Artemisinin and their derivatives which today are novel antimalarial therapy, evidence of resistance have been detected in five countries of the Greater Mekong subregion: Cambodia, Lao People's Democratic Republic, Myanmar, Thailand and Vietnam (WHO, 2016).

The in vitro assay provides information on $P$. falciparum response to antimalarial drug irrespective of the patient's immune status, it also helped as epidemiological tool for assessing baseline sensitivity and monitoring the drug response of $P$. falciparum over time and place (WHO, 2001). More so, it provides background information for the development and evaluation of drug policies over time. A therapeutic failure is showed by changes in the parasite sensitivity pattern in vitro and is not disturbed by ongoing malaria transmission, unlike in vivo assay (WHO, 2001). The efficacy of any antimalarial drug depends on its ability to kill by interrupting the basic metabolic functions essential for the survival on the parasite. This leads to reduced multiplication and paving way for the immune system to remove the damaged parasites from circulation.

This study was designed to highlight reported malaria prevalence and drug prescription profiles with the in vitro susceptibility of $P$. falciparum to some selected antimalarial drugs reportedly prescribed for malaria treatment in Bauchi North East, Nigeria.

\section{MATERIALS AND METHODS \\ Study area}

The study was carried out at The Specialist Hospital Bauchi, Bauchi metropolis, Bauchi State, Nigeria. It is a government owned health facility and majority of the attendees' were from low to moderate socio-economic groups. The health facility was easily accessible to most residents of Bauchi metropolis and its neighboring Local Government Areas. Bauchi State is located in North-East region of Nigeria having 20 Local Government Areas and majority of the indigenous tribes are Hausa and Fulani. Bauchi State has a total land area of 49,119 $\mathrm{km}^{2}$ and located between latitude $9^{\circ} 3^{\prime}$ and $12^{\circ}$ 
3 north and longitude $8^{\circ} 50^{\prime}$ and $11^{\circ}$ east. The rainfall ranges between 1,300 millimeters in the south and 700 millimeters per annum to the north. The State has an estimated population of 4.7 million people according to the 2006 census and bordered by seven States.

\section{Ethical approval}

Ethical clearance was obtained from Bauchi State Ministry of Health Ethical Committee with protocol approval No: NREC/12/05/2013/2017/57 and consent from Specialist Hospital Management Board (SHB/ADM/17/1).

\section{Retrospective study}

A retrospective study was carried out to determine the incidence of malaria for three years. Reported cases of malaria from 2015, 2016 and 2017 were compiled from the malaria patients' medical records. The information collected include Gender, Age, Socio-economic Status, Ethnic Group and prescribed antimalarial drugs sampled from patients records within 2015-2017.

\section{Study population}

One hundred and twenty two blood samples were collected from fever related patients attending the General Out- Patient department, Specialist Hospital Bauchi, Nigeria between April to September, 2018 and screened for $P$. falciparum infection using sample size proposed by (Fischer et al., 1991).

\section{Sample collection}

Clinical blood samples of patients visiting Specialist Hospital Bauchi who had history of fever were sampled by a hospital clinician/Medical Laboratory scientist. An approximately $3 \mathrm{ml}$ blood samples were collected in sterilized syringes and dispensed into sterile EDTA tubes treated with Gentamicin to minimize contamination. These blood samples were transported immediately within 6 hours to Pharmaceutical Microbiology Laboratory, Ahmadu Bello University Zaria and processed within 24 hours prior to collection.

\section{Antimalarial drugs}

Quinine (Alpha Lab. Ltd), Chloroquine (Sigma Adrich), Artemether (Zhejiang Tianfeng Pharm. Fac.) and Coartem (Artemether-Lumefantrine) (Novartis Pharma) combination.

\section{Microscopic examination}

Thick and thin films were prepared for microscopic examination of the Plasmodium species. Thin films were fixed with methanol for 60 seconds, rinsed gently and allowed to dry. Both blood films were stained with (10\% $\mathrm{vol} / \mathrm{vol})$ Giemsa of $\mathrm{pH} 7.1$ for 10 minutes (Nnamdi et al., 2015). Films were allowed to dry for 30 minutes and were observed under the microscope using x 100 (Oil immersion) objective lens. The thin films were used to identify the parasite species while the thick films were used to determine the parasite density. Average parasite counts per 10 microscopic fields were determined and multiplied by a factor of 500 to estimate the number of parasites per microliter of blood (Greenwood and Amstrong, 1991). Patient's blood samples with parasitemia level within $1000 / \mu \mathrm{L}-80,000 / \mu \mathrm{L}$ were recruited for the in-vitro antimalarial susceptibility test.

\section{Preparation of culture medium}

Malaria culture medium was prepared by dissolving $10.4 \mathrm{~g}$ RPMI 1640 powder (Sigma Aldrich), $5.94 \mathrm{~g}$ of HEPES (Sigma Aldrich), and $0.625 \mathrm{~mL}$ Gentamicin (Jiangsu Huayang Pharm.) from $40 \mathrm{mg} / \mathrm{ml}$ stock in 900 $\mathrm{mL}$ of sterile distilled-deionised water. Sterile distilled-deionised water was topped to 960 $\mathrm{mL}$, then filtered using $0.22 \mu \mathrm{M}$ membrane filter and stored at $4{ }^{\circ} \mathrm{C}$. Before cultivation, every aliquot was supplemented $4.2 \mathrm{~mL}$ of $(5 \% \mathrm{wt} / \mathrm{vol}) \mathrm{NaHCO}_{3}$ and final addition $(10 \%$ $\mathrm{vol} / \mathrm{vol}$ ) serum from $\mathrm{O}^{+}$human blood to make complete blood medium mixtures (Basco, 2007).

\section{Drug preparation}

The selected antimalarial agents were prepared in their appropriate solvents. Stock solutions were prepared in $(70 \% \mathrm{vol} / \mathrm{vol})$ ethanol for Chloroquine and Artemether; and 
in sterile distilled water for quinine and Coartem (Artemether-Lumefantrine). Five graded solutions were prepared in absolute ethanol and distributed into 96-well flatbottom micro-titer plates.

\section{Drug assay}

Antimalarial agent susceptibility of $P$ falciparum isolates assay was carried using the method described by Singh et al. (2015). For in vitro assay, $10 \mu \mathrm{L}$ of the antimalarial agent was dispensed in well $\mathrm{B}-\mathrm{F}$ of graded concentrations (well A was without drug). The solutions were left to dry to powder. Ninety microliter of complete culture blood medium mixtures (RPMI 1640 and $\mathrm{O}^{+}$serum) was added into each well (A-F), then finally $10 \mu \mathrm{L}$ of the standardized parasitized erythrocytes dispensed into each of the wells. This was done under strict aseptic condition. The plates were gently mixed by shaking without lifting it from the laboratory bench. The plates were incubated in anaerobic incubator $\left(5 \% \mathrm{CO}_{2}\right)$ in at $37{ }^{\circ} \mathrm{C}$ for 30 hours (Trager and Jensen, 1976). After incubation, the plates were allowed to stand for 30 minutes in a semivertical position $\left(40{ }^{\circ} \mathrm{C}\right.$ inclined). The red cells decants were transferred to a clean grease free microscope slide by removing the supernatant from each well. The smears were allowed to dry for 24 hours and stained with $(5 \% \mathrm{vol} / \mathrm{vol})$ Giemsa for 30 minutes.

\section{Examination of post culture slides and $\mathrm{IC}_{50}$ determination}

The stained thick films were examined under oil immersion objective (x100) lens and parasite densities (number) were counted and related with the parasite density in the control well.

Schizont growth inhibition was counted in 10 microscopic fields. The control parasite culture freed from test antimalarial agents were considered as $100 \%$ growth. The percentage inhibition per concentration was calculated using the formula: [ $\%$ parasitaemia in control wells - $\%$ parasitaemia of test wells)/ (\% parasitaemia of the control)] x 100 (WHO, 2001; Ngbolua et al., 2011). The $\mathrm{IC}_{50}$ values, the concentration required to inhibit schizont growth by $50 \%$ were determined by linear regression analysis using Microsoft excel 2007 from the schizont growth inhibition curves (Log of concentration versus percent inhibition) generated from each parasite-drug interaction (Jimoh et al., 2019). Drug resistant $P$. falciparum parasites were identified with $\mathrm{IC}_{50}$ values greater than the peak plasma concentration of the Antimalarial drugs.

\section{RESULTS \\ Retrospective survey}

In this survey, the overall percentage prevalence of malaria in the health facility from 2015 through 2017 was computed as $22.78 \%$. The monthly distribution of malaria cases from three full calendar years is presented in Figure 1. The total number of reported percentage prevalence in full calendar years of malaria in 2015, 2016 and 2017 to be $22.92,24.38$ and 21.04 respectively. The peak average cases of malaria was revealed during the raining periods of April to October.

The reported malaria cases in 2015 were 110 . Out of this figure, $66(13.75 \%)$ were females while the males were reported to have $44(9.17 \%)$ malaria cases Table 1. Similarly in 2016, the malaria cases among females were reported to be $68(14.17 \%)$ compared to male with $49(10.2 \%)$. Females' recorded $56(11.67 \%)$ cases in 2017 while males have $45(9.38 \%)$ numbers of reported cases in the health facility out of 480 cards sampled GOPD each year.

The incidence of malaria based on their socio-economic status is shown in Table 2. High incident rate was reported from 2015 through 2017 among house wives with an average of $(27.67 \%)$ respectively. On the other hand, the prevalent rate reported among civil servants, students and business people were reported considerably low. The results clearly showed that there was reported high malaria prevalent rate among Hausa speaking tribe of $17.71 \%$ in $2015,20.42 \%$ in 2016 and $15.42 \%$ in 2017 . The prevalent rate of malaria among the Fulani ethnic group was reported lower compared to Hausa. Sayawa, Jarawa and other tribal groups were reported significantly lower Table 3. 
Age limit wise, the highest prevalence of malaria cases fell within age group $1-17$ with $14.10 \%$ while age group 18 and above recorded $8.68 \%$ from January 2015 to December 2017. The malaria prevalence among age group $1-17$ were found to be $14.17 \%, 16.04 \%$ and $12.08 \%$ in 2015,2016 and 2017 respectively; however among age group 18 and above, $8.75 \%$ was revealed in 2015, 8.33 in 2016 and $8.96 \%$ in 2017 Table 4.

\section{Prescription pattern of antimalarial drug in Specialist Hospital Bauchi, Nigeria}

The study revealed SulfadoxinePyrimethamine, Artesunate or Artemether and Artemether-Lumefantrine (ACT) were the frequently prescribed antimalarial therapeutic agents in the studied health facility in Bauchi, Nigeria Table 5. Artemether-Lumefantrine (ACT) however was highly prescribed antimalarial agent for the period of three years Table 5. ACT was recommended as the first line of treatment of uncomplicated malaria by World Health Organisation and adopted as a policy in Nigeria in 2004 (FMH, 2005). High prescription of Artemether-Lumefantrine (ACT) was reported in 2015 and 2016 with $91.82 \%$ and $93.16 \%$ followed by a drop in
2017 with 79.20\%. The average use of Artemether-Lumefantrine (ACT) in the health facility from 2015 to 2017 was $88.06 \%$. The health facility indicated $15.84 \%$ use of Arthemeter or Artesunate mono-therapy in 2017; however in 2015, it dropped to $8.18 \%$. The prescription of Sulphadoxinepyrimethamine and Quinine were observed to be prescribed low in 2017 at $3.96 \%$ and $0.99 \%$ respectively for reported malaria patients.

\section{In vitro susceptibility pattern antimalarial agents}

In vitro anti-malarial agent tests were carried out and the $\mathrm{IC}_{50}$ for each antimalarial drug determined. $\mathrm{IC}_{50}$ implies that $50 \%$ of the parasite could not mature to schizont stage at that drug concentration. A total of 122 blood samples were collected and recruited for the study. Eighty five $P$. falciparum isolates were successfully investigated for in vitro susceptibility response to four antimalarial agents. Twenty three (23/85) $27.06 \%$ isolates of $P$. falciparum were resistant to Chloroquine, (16/85) $18.82 \%$ to Coartem (Artemether-Lumefantrine), (12/85) $14.12 \%$ $P$. falciparum isolates were resistant to Artemether and (4/85) $4.71 \%$ to Quinine Table 6.

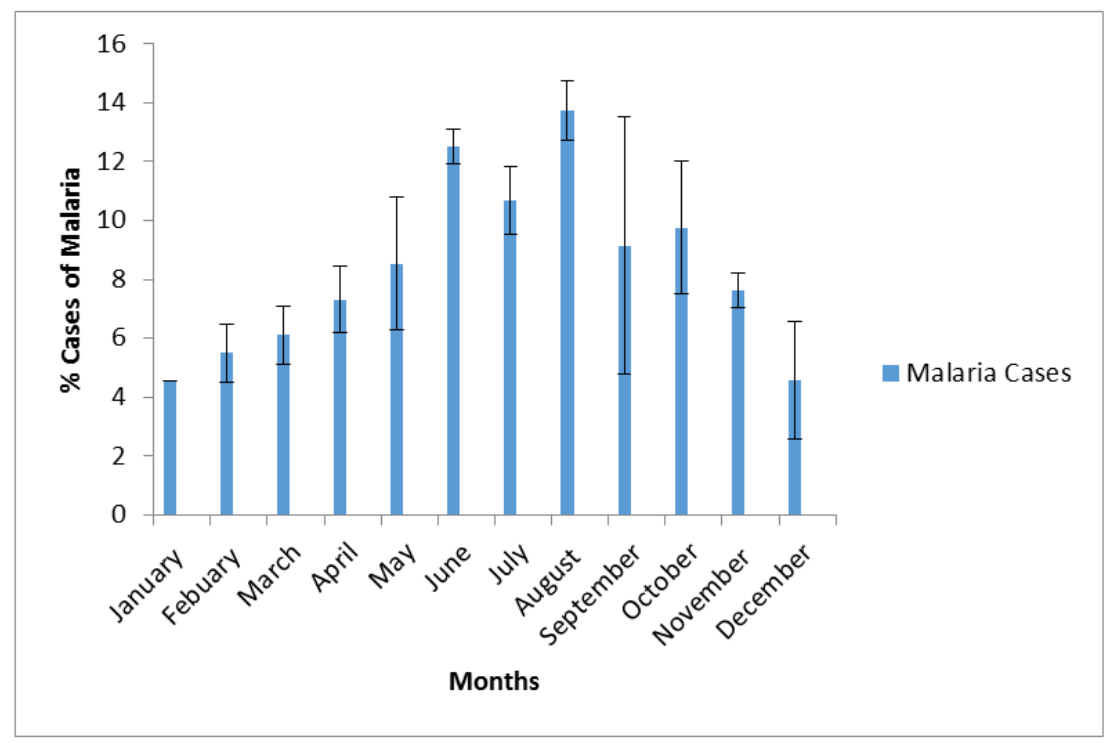

Figure 1: Monthly trends of reported percentage cases of malaria in Specialist Hospital Bauchi from 2015-2017 ( $n=480$ per year). 
Table 1: Prevalent rate of reported malaria cases among male and female patients in Specialist Hospital Bauchi, Nigeria from 2015 to 2017.

\begin{tabular}{ccc}
\hline Year & \multicolumn{3}{c}{ Gender } \\
\cline { 2 - 3 } & Male (\%) & Female (\%) \\
& $\boldsymbol{n = 4 8 0}$ & $\boldsymbol{n = 4 8 0}$ \\
\hline $\mathbf{2 0 1 5}$ & $44(9.17)$ & $66(13.75)$ \\
$\mathbf{2 0 1 6}$ & $49(10.2)$ & $68(14.17)$ \\
$\mathbf{2 0 1 7}$ & $45(9.38)$ & $56(11.67)$ \\
Mean \pm SD & $9.58 \pm 0.44$ & $13.19 \pm 1.09$ \\
\hline
\end{tabular}

$\mathrm{SD}=$ Standard Deviation.

Table 2: Prevalent rate of reported malaria cases among different socio-economic groups of patients in Specialist Hospital Bauchi, Nigeria from 2015 to 2017.

\begin{tabular}{ccccc}
\hline $\begin{array}{c}\text { Malaria socio-economic } \\
\text { patient groups }\end{array}$ & $\begin{array}{c}\mathbf{2 0 1 5} \\
(\boldsymbol{n = 4 8 0 )}\end{array}$ & $\begin{array}{c}\mathbf{2 0 1 6} \\
(\boldsymbol{n = 4 8 0})\end{array}$ & $\begin{array}{c}\mathbf{2 0 1 7} \\
(\boldsymbol{n}=\mathbf{4 8 0})\end{array}$ & Mean \pm SD \\
\hline House wives & $31(6.46)$ & $29(6.04)$ & $23(4.79)$ & $27.67 \pm 3.40$ \\
Civil servants & 0 & $4(0.83)$ & $6(1.25)$ & $3.33 \pm 2.50$ \\
Students & $14(2.92)$ & $3(0.63)$ & $17(3.54)$ & $11.33 \pm 6.02$ \\
Business people & $1(0.21)$ & $6(1.25)$ & $2(0.42)$ & $3.00 \pm 2.16$ \\
\hline
\end{tabular}

Table 3: Prevalent rate of reported malaria cases among ethnic different diversity of patients in Specialist Hospital Bauchi, Nigeria from 2015 to 2017.

\begin{tabular}{ccccc}
\hline $\begin{array}{c}\text { Malaria patient } \\
\text { ethnic groups }(\%)\end{array}$ & $\begin{array}{c}\mathbf{2 0 1 5} \\
(\boldsymbol{n}=\mathbf{4 8 0})\end{array}$ & $\begin{array}{c}\mathbf{2 0 1 6} \\
(\boldsymbol{n}=\mathbf{4 8 0})\end{array}$ & $\begin{array}{c}\mathbf{2 0 1 7} \\
(\boldsymbol{n}=\mathbf{4 8 0})\end{array}$ & Mean \pm SD \\
\hline Hausa & $85(17.71)$ & $98(20.42)$ & $74(15.42)$ & $17.85 \pm 2.04$ \\
Fulani & $13(2.71)$ & $13(2.71)$ & $19(3.96)$ & $15.00 \pm 0.59$ \\
Sayawa & $0(2.92)$ & 0 & $1(0.21)$ & $0.33 \pm 1.33$ \\
Jarawa & $3(0.63)$ & $1(0.21)$ & $0(0)$ & $1.33 \pm 0.26$ \\
Others & $7(1.46)$ & $5(1.04)$ & $8(1.67)$ & $6.67 \pm 0.26$ \\
\hline
\end{tabular}

Table 4: Reported prevalence of malaria cases in respect to age distribution.

\begin{tabular}{cccc}
\hline Year $(\boldsymbol{n}=\mathbf{4 8 0})$ & $\mathbf{0 - 1 7}(\boldsymbol{\%})$ & $>\mathbf{1 8}(\boldsymbol{\%})$ & Total \\
\hline $\mathbf{2 0 1 5}$ & $68(14.17)$ & $42(8.75)$ & 110 \\
$\mathbf{2 0 1 6}$ & $77(16.04)$ & $40(8.33)$ & 117 \\
$\mathbf{2 0 1 7}$ & $58(12.08)$ & $43(8.96)$ & 101 \\
Mean \pm SD & $14.10 \pm 1.62$ & $8.68 \pm 0.26$ & \\
\hline
\end{tabular}

$\mathrm{SD}=$ Standard Deviation. 
Table 5: Profile of antimalarial drugs prescriptions for malarial patients in Specialist Hospital Bauchi, Nigeria from 2015 to 2017 (\%).

\begin{tabular}{ccccc}
\hline Drugs prescribed & $\begin{array}{c}\mathbf{2 0 1 5} \\
(\boldsymbol{n = 1 1 0})\end{array}$ & $\begin{array}{c}\mathbf{2 0 1 6} \\
(\boldsymbol{n = 1 1 7})\end{array}$ & $\begin{array}{c}\mathbf{2 0 1 7} \\
(\boldsymbol{n}=\mathbf{1 0 1})\end{array}$ & Mean \pm SD \\
\hline ACT & 91.82 & 93.16 & 79.20 & $88.06 \pm 6.29$ \\
Arthemeter/Artesunate & 8.18 & 6.84 & 15.84 & $10.29 \pm 3.96$ \\
SP & 0.00 & 0.00 & 3.96 & $1.98 \pm 1.87$ \\
Quinine & 0.00 & 0.00 & 0.99 & $0.33 \pm 0.47$ \\
\hline SP=Sulphadoxine/pyrimethamine ACT= Artemisnin based Combined Therapy, SD= Standard Deviation.
\end{tabular}

Table 6: Range of $\mathrm{IC}_{50}$ of test anti-malarial agents results against Plasmodium falciparum isolates from 85 malaria patients in Specialist Hospital Bauchi, Nigeria.

\begin{tabular}{cccc}
\hline $\begin{array}{c}\text { Antimalarial } \\
\text { agent }\end{array}$ & Range of $\mathbf{I C}_{\mathbf{5 0}}(\boldsymbol{\mu M o l})$ & $\begin{array}{c}\text { Resistant } \boldsymbol{P} \text {. falciparum } \\
\text { isolates }(\boldsymbol{\%})\end{array}$ & $\begin{array}{c}\text { Resistance } \\
\text { threshold }(\boldsymbol{\mu M o l})\end{array}$ \\
\hline CQ & $0.11-13.06$ & $23(27.06)$ & $>4.47$ \\
QN & $2.90-79.87$ & $4(4.71)$ & $>55.17$ \\
AR-LUM & $8.04-194.83$ & $16(18.82)$ & $>53.50$ \\
AR & $0.03-5.13$ & $12(14.12)$ & $>1.81$ \\
\hline
\end{tabular}

CQ: Chloroquine, QN: Quinine, AR: Artemether, LUM: Lumefantrine.

\section{DISCUSSION}

Malaria a prevalent tropical disease in sub-Saharan Africa that accounted for the highest global mortality of $584000(90 \%)$ in 2013 (Mfopa et al., 2017). About 50\% of the Nigerian population will have at least one episode of malaria annually while children below the age of five (about 24 million) will have two to four attacks annually (WHO, 2016). The resistance of Plasmodium falciparum to various antimalarial agents have become a big concern as it poses a major obstacle to the control of malaria. The study has shown an overall $22.78 \%$ prevalence of malaria from the survey conducted at Specialist Hospital Bauchi. The prevalent observed from this survey is consistent with the finding of Aliyu et al. (2017) who reported $22.4 \%$ prevalence in Kaduna metropolis, Nigeria and $21.1 \%$ by Igbengbu et al. (2011) in the Iwo community in Southwestern Nigeria. The prevalence finding of Edogun et al. (2017) was higher than that of Aliyu et al. and Igbengbu et al. with $51.9 \%$ in Niger State, North Central Nigeria. In a study conducted by Sam-wobo et al. (2014), higher prevalence rate of $71.1 \%$ in seven primary health centers of four local governments in Ogun State Nigeria was reported. This variation of prevalence rate could be as a result of differences in time and area where these studies were conducted. The reported result of malaria cases obtained from this study was a period of three years consecutively. Trend analysis of malaria cases from this study revealed increases in the number of malaria cases as rainfall begins from the Month of April to October. This indicates a direct relationship between rainfall and malaria transmission resulting in the availability of breeding site for the mosquito vector hence leading to the spread of the disease.

The survey showed that the prevalence of malaria cases were more among the female gender than the male. This observation agreed with workers' reports on malaria (Edogun et 
al., 2017; Nas et al., 2017). This increase in prevalence among females that reported for medical advice could be as result of decreased immunity particularly among pregnant women that make them more susceptible to infection (Nas et al., 2017). However, the study debunks the finding of Nwaorgu and Orajaka (2011) whose result showed increased infection rate in males to females.

The study also disclosed that age group $0-17$, has the highest reported average prevalence which accounted for 14.09\%. Adults of $>18$ years have the least average prevalence of $8.68 \%$. This finding is related with the work of Nas et al. (2017) who revealed the highest incident rate of $87 \%$ among age range of $0-10$ in Kano State, Nigeria. Similarly, Adepeju (2017) observed that age group $<20$ recorded the highest malaria prevalence cases (68.4\%) in Akure, Ondo State, Nigeria. Edogun et al. (2017) finding also showed increased prevalence of $56.6 \%$ among age limit $1-15$ years to $41.33 \%$ of above 16 years in Niger State, Nigeria. Prevalence of malaria in relation to age showed a decreasing trend towards an increasing age. The highest prevalence among age limit of $1-17$ suggest that their immunity was not fully developed; subsequently they were unable to resist infection (Nas et al., 2017). Malnutrition can also contribute to high prevalence of malaria among this age group (Edogun et al., 2017).

Based on the result of this study, the average prevalence of $27.67 \%$ was reported among house-wives who showed higher prevalence of malaria compared to other socio-economic status. This finding is indistinguishable with that obtained by Nas et al. (2017) revealing that house-wives have the highest prevalence in that category with $64.53 \%$. It is a norm among the Hausa culture that house-wives are restricted in conducting any socio-economic activities and compelled to stay at home, hence making them economically dependent on their husbands. They may be unable to access prompt treatment and purchase of Insecticide Treated Nets for themselves and their wards. It is also eminent that pregnancy among house-wives often predisposes them to malaria infection and other diseases because of decreased immunity during pregnancy and breastfeeding (Nas et al., 2017). In some societies like that obtained in Northern part Nigeria, women are obliged to get up before sunrise to perform house hold chores, exposing themselves to mosquito bites and thus leading to malaria infection (Heggenhougen et al., 2003).

High prescription of ArtemetherLumefantrine (Artemisinin Combination Therapy ACT) was revealed from the survey. This result agrees with the policy of the Federal Ministry of Health on Antimalarial drugs for the treatment of uncomplicated malaria that showed ACTs as first Line of treatment for uncomplicated malaria (FMH, 2005).

We found that in this study, $27.06 \%$ of isolates of $P$. falciparum were resistant to Chloroquine. Similar finding was reported by Shujatullah et al. (2012) of $24.07 \%$ from Aligarh. Umar et al. (2017) observed 94.9\% resistance to Chloroquine among pregnant women in Kaduna, Nigeria while Peletri et al. (2012) reported slightly lower resistance of $P$. falciparum isolates of $88.9 \%$ to Chloroquine in Abuja, Nigeria to that of Umar et al. Moderate resistance of $68.9 \%$ was revealed in studies conducted by Olasehinde et al. (2014) in Ogun State, Nigeria. The probable reason for the reported varied cases of resistance to Chloroquine in the different health facilities could be attributed to abuse of the Chloroquine among patients living in these endemic areas. The use of Chloroquine has since been discouraged in Nigeria (FMH, 2005).

One of the ACTs recommended as the first-line treatment for uncomplicated $P$. falciparum malaria in Nigeria is the combination of Artemether-Lumefantrine. About $18.82 \%$ of the P. falciparum isolates in this study presented reduced susceptibility to Artemether-Lumefantrine combination. Falade et al. (2005) has reported a similar test $P$. falciparum isolates of $14 \%$ reduction in susceptibility to Artemether-Lumefantrine among African Children. This hike in reduced activity could be attributed to the 
indiscriminate use of the ArtemetherLumefantrine drug as it can be easily purchased in Pharmaceutical stores throughout Nigeria without prescription. On the other hand, $100 \%$ susceptibility of $P$. falciparum to Artemether-Lumefantrine has been reported by Aminu et al. (2017) from Kano and Katsina States, Nigeria. It is now evident that efficacy of Artemisinin based combinations will soon be compromised with the emergence of multiple Antimalarial resistant $P$. falciparum in this study $(18.82 \%)$.

In vitro susceptibility of $P$. falciparum isolates to Artemether was observed to witness $14.12 \%$ resistant $P$. falciparum. Reports of rise in $\mathrm{IC}_{50}$ values in vitro in French Guiana $P$. falciparum strains to Artemisinin derivative (Artemether) have been documented (Jambou et al., 2005). In Nigeria, Umar et al. (2017) revealed a resistance of $38 \%$ to Artemether in vitro among pregnant women in Kaduna State. Furthermore, Sadiq et al. (2015) reported 50\% percentage reduced effectiveness of Artemether against $P$. falciparum in Kano, Nigeria. The researchers suggested that either the quality of the drug was being compromised or the patients did not comply with the right regimen.

Quinine was observed to retain high activity against test $P$. falciparum with only $4.71 \%$ resistant isolates. This result agreed with the findings of Fall et al. (2011) and Fall et al. (2015) who reported $6 \%$ and $5.6 \%$ resistant P. falciparum isolates in Dakar, Senegal. Resistant P. falciparum to Quinine (27.8\%) was also reported by Peletri et al. (2012) at Abuja, Nigeria. However, Ipka et al. (2010) and Olasehinde et al. (2014) reported $100 \%$ P. falciparum isolates susceptibility to quinine in north central Nigeria and South western Nigeria respectively. Quinine has been the primary drug for the treatment of severe and drug resistant malaria, usually under medical monitoring in Nigerian (WHO, 2018). The very low in vitro $P$. falciparum resistance to quinine in this study is a clear indication of $P$. falciparum susceptibility to quinine in Nigeria and hence its continued relevance for resolving malaria burden where its effectiveness is prominent.

\section{Conclusion}

The survey revealed a moderate prevalence rate of malaria infection in Bauchi State, Nigeria. The infection was found to affect more females than males and patients below 17 years of age. The study also showed that the disease is more pronounced among Hausa house-wives with low income in relation to Civil servants and other socioeconomic groups. This is a clear indication of the tremendous effect of malaria and the need for urgent intervention especially in developing world.

Reduced effectiveness was observed in all the tested Antimalarial agents in this study namely; Chloroquine, ArtemetherLumefantrine, Artemether and Quinine. Emergence of multiple antimalarial resistant $P$. falciparum is serious threat to the control of malaria infection in Bauchi, Nigeria. Hence, to avoid future malaria epidemics in all regions, it is crucial to act now to curtail the spread of Artemisinin resistant parasites before the ACT totally loses its potency.

\section{COMPETING INTERESTS}

The authors declare there are no competing interest.

\section{AUTHORS' CONTRIBUTIONS}

Experimental design: JOE and ADA. Collection of Sample and Laboratory experiments: FSJ, ADA, JYA and FOS. Data analysis: ADA and JOE. Planning and supervision of experiments and manuscript: JOE and RAO. All authors read and approved the final manuscript.

\section{ACKNOWLEDGEMENTS}

This work is a part of M.Sc. research sponsored by Mr. D.I Ijikon School of General Studies Abubakar Tatari Ali Polytechnic, Bauchi. The provision of facilities by the Department of Pharmaceutics and Pharmaceutical Microbiology Ahmadu Bello University, Zaria is highly appreciated. The Authors acknowledge the staff of 
Parasitology Department, Specialist Hospital Bauchi for their support, co-operation and sample provision. The effort of Prof. J O. Ehinmidu and Prof. Mrs. Rukayat Avosuahi Oyi, Department of Pharmaceutics and Pharmaceutical Microbiology, Ahmadu Bello University, Zaria, Kaduna State, Nigeria is highly acknowledged for supervising and reading the manuscript. Our gratitude also goes to Bauchi State Ministry of Health for providing us with ethical clearance to enable us carryout this research.

\section{REFERENCES}

Adepeju IS. 2017. Prevalence of Malaria Parasite among Asymptomatic and Symptomatic Students of Federal University of Technology, Akure, Ondo State. Br. J. Res., 4: 5. DOI: http:/ /dx.doi.org/10.21767/2394-3718.100005.

Aliyu MM, Nasir AI, Yahaya Abdullahi Umar AY, Vanstawa PA, Medugu TJ, UA, Amadu OD. 2017. Prevalence, risk factors, and antimalarial resistance patterns of falciparum plasmodiasis among pregnant women in Kaduna metropolis, Nigeria. Ci Ji Yi Xue Za Zhi., 29(2):

98-103.

DOI: http://dx.doi.org/10.4103/tcmj.tcmj _22_17.

Aminu BM, Mukhtar MD. 2017. In vitro efficacy of act drug son Plasmodium falciparum clinical isolates from Kano and Katsina States, Nigeria. Bayero $J$. Pure App. Sci., 10(1): 49-52. DOI: http://dx.doi.org/10.4314/bajopas.v10i1. $10 \mathrm{~S}$.

Basco L. 2007. Field Application of in vitro Assays for the Sensitivity of Human Malaria Parasites to Antimalarial Drugs. World Health Organization: Geneva.

Builders IM, Degge H, Peter YJ, Ogbole E. 2014. Prescription Pattern of Antimalarial Drugs in a Teaching Hospital in Nigeria. Brt. Biomed. Bull., 2(1): 267-276.

Edogun AH, Daramola OG, Esan OC, Edungbola DI. 2017. Prevalence of Malaria Parasitaemia in Three Selected
Local Government Areas of Niger State, North Central, Nigeria. J. A. B.B., 16(3): 1-9.

DOI:

http://dx.doi.org/10.9734/JABB/2017/37 884.

Falade C, Makanga M, Premji Z, Ortmann C, Stockmeyer M, Ibarra de Palacios P. 2005. Efficacy and safety of artemetherlumefantrine $\left(\right.$ Coartem $\left.^{\circledR}\right)$ tablets (sixdose regimen) in African infants and children with acute, uncomplicated falciparum malaria. R. Soc. Trop. Med. Hyg., 99(6): 459-467. DOI: http://dx.doi.org/10.1016/j.trstmh.2004.0 9.013

Fall B, Camara C, Fall M, Nakoulima A, Dionne P, Diatta B, Pradines B. 2015. Plasmodium falciparum susceptibility to standard and potential anti-malarial drugs in Dakar, Senegal, during the 2013-2014 malaria season. Malar. J., 14(1): $60 . \quad$ DOI: http://dx.doi.org/10.1186/s12936-0150589-3.

Fall B, Diawara S, Sow K, Baret E, Diatta B, Fall KB, Pradines B. 2011. Ex vivo susceptibility of Plasmodium falciparum isolates from Dakar, Senegal, to seven standard anti-malarial drugs. Malar. J., 10(1): $\quad 310 . \quad$ DOI: http://dx.doi.org/10.1186/1475-2875-10310.

Federal Ministry of Health. 2005. National Guidelines for Diagnosis and Treatment of Malaria (3rd edn). Federal Ministry of Health: Abuja, Nigeria.

Fischer G, Lemke AC, McCall R, Morch A. 1991. Making argumentation serve interaction in human computer-special issue on design rationale. HumanCmptr. Interactn., 6(3-4): 13-63. DOI: http://dx.doi.org/10.1080/07370024.1991 .9667173.

Greenwood BM, Armstrong JR. 1991. Comparison of two simple methods for determining malaria parasite density. Trans. R. Soc. Trop. Med. Hyg., 85(2): 186-188.

DOI: http://dx.doi.org/10.1016/00359203(91)90015-Q. 
Gbotosho GO, Happi1 CT, Ganiyu A, Ogundahunsi OA, Sowunmi A, Oduola AM. 2009. Potential contribution of prescription practices to the emergence and spread of Chloroquine resistance in south-west Nigeria: caution in the use of Artemisinin combination therapy. Malar. J., $\quad$ 8(1): $313 . \quad$ DOI: http://dx.doi.org/10.1186/1475-2875-8313.

Heggenhougen HK, Hackelhal V, Vivek P. 2003. Gender relations and special roles of women in malaria risk and control. In The behavior and social aspect of malaria and its control, Pasternack S(ed). SEB: Geneva; 109-110.

Igbeneghu $\mathrm{C}$, Odaibo $\mathrm{AB}$, Olaleye $\mathrm{DO}$. 2011. Impact of asymptomatic malaria on some hematological parameters in the Iwo community in Southwestern Nigeria. Med. Princ. Pract., 20: 459463. DOI: http://dx.doi.org/10.1159/000327673.

Ikpa TF, Ajayi JA, Imandeh GN, Usar JI. 2010. In Vitro Surveillance of Drug Resistant Falciparum Malaria in North Central Nigeria. Afr. J. Cln. Exper. Microbiol., 11(2): 111-119. DOI: http://dx.doi.org/10.4314/ajcem.v11i2.53 917.

Jambou R, Legrand E, Niang M, Khim N, Lim P, Volney B, Ekala MT, Bouchier C, Esterre P, Fandeur T, MercereauPuijalon O. 2005. Resistance of Plasmodium falciparum field isolates to in-vitro artemether and point mutations of the SERCA-type PfATPase6. The Lancet, 366(9501): 1960-1963. DOI: http://dx.doi.org/10.1016/s0140-6736 (05)67787-2.

Jimoh AA, Maiha BB, Chindo BA, Ejiofor JI, Ehinmidu JO, Atang DA, Azi JY.2019. In vitro Antiplasmodial Activity of Methanol Stem Extract of Costus afer Ker Gawl. (Costaceae) and its Residual Aqueous Fraction against Some Drugsensitive and Drug-resistant Plasmodium falciparum Strains. Trop. J. Nat. Prod. Res., 3(5): 162-169. DOI: http://dx.doi.org/ 10.26538/tjnpr/v3i5.3.
Laxminarayan R, Gelband H. 2009. A Global Subsidy: Key to affordable drugs for Malaria. Health Affairs, 28(4): 949-961. DOI:

http://dx.doi.org 10.1377/hlthaff.28.4.949.

Mfopa AN, Mbouna CDJ, Tchokouaha LRY, Tchuente MAT, Kouipou RMT, Fokou PVT, Kemgne EAM, Kamkumo RG, Boyom FF. 2017. In vitro and in vivo antiplasmodial activity of extracts from Polyalthia suaveolens, Uvaria angolensis and Monodora tenuifolia (Annonaceae). Int. J. Biol. Chem. Sci., 11(1): $118 . \quad$ DOI: http://dx.doi.org/10.4314/ijbcs.v11i1.10.

Nas FS, Yahaya A, Ali M.2017. Prevalence of Malaria with Respect to Age, Gender and Socio-Economic Status of Fever Related Patients in Kano City, Nigeria. Greener J. epid. publ. Health, 5(5): 044049.

DOI: http://dx.doi.org/10.15580/GJEPH.2017. 5.091017126.

Ngbolua K, Rakotoarimanana H, Rafatro H, Ratsimamanga U, Mudogo V, Mpiana P, Tshibangu D. 2011. Comparative antimalarial and cytotoxic activities of two Vernonia species: V. amygdalina from the Democratic Republic of Congo and $V$. cinerea subsp vialis endemic to Madagascar. Int. J. Biol. Chem. Sci., 5(1): 345-353. DOI: http://dx.doi.org/10.4314/ijbcs.v5i1.6811 1.

Nnamdi S, Uju Dibua M, Ikpa T. 2015. Screening of fruit pulp extracts of Picralima nitida against in vitro cultures of Plasmodium falciparum and acute oral toxicity in white albino mice. Int. J. Biol. Chem. Sci., 9(1): 430. DOI: http://dx.doi.org/10.4314/ijbcs.v9i1.36.

Nwaorgu OC, Orajaka BN. 2011. Prevalence of Malaria among Children $1-10$ Years Old in Communities in Awka North Local Government Area, Anambra State South East Nigeria. Af. R. Rev., 5(5):264281.

DOI: http://dx.doi.org/10.4314/afrrev.v5i5.21.

Olasehinde GI, Ojurongbe O, Adeyeba AO, Fagade OE, Valecha N, Ayanda IO, 
Egwari LO. 2014. In vitro studies on the sensitivity pattern of Plasmodium falciparum to anti-malarial drugs and local herbal extracts. Malar. J., 13(1): 63. DOI: http://dx.doi.org/10.1186/14752875-13-63.

Peletri I, Matur B, Ibecheozor N, Ihongbe J, Wakama T. 2012. In-Vitro Susceptibility of Plasmodium falciparum to Antimalarial Drugs in Abuja, Nigeria. Inet. J. Parasitic Dis., 5: 1. DOI: http://dx.doi.org/10.4314/njpar.v31i2.69 479.

Sadiq Y, Maikaje BD, Sarkin-Fada F, Darma AB, Usman SS. 2015. Occurrence of $P$. falciparum resistance to artemisininbased combination therapy for malaria in Kano State, Nigeria. Ann. Exp. Bio., 3(1): 33-38.

Sam-Wobo SO, Adekunle NO, Adeleke MA, Dedeke GA, Oke OA, Abimbola WA, Surakat OA. 2014. Epidemiological Factors in Prevalence of Malaria Parasites in Primary Health Facilities Attendees, Ogun State, Nigeria. Malar. Chemoth. Cont. Elim., 3: 111. DOI: http://dx.doi.org/10.4172/ 20902778.1000111.

Shujatullah F, Khan HM, Khatoon A, Khan PA, Ashfaq M. 2012. In vitro chloroquine resistance in Plasmodium falciparum isolates from tertiary care hospital. Hindawi Publishing Corporation. Malar. Res. Treat., 2012: $1-4$.

DOI: http://dx.doi.org/10.1155/2012/538481.

Singh G, Urhekar DA, Raksha. 2015. In Vitro Antimalarial Drug Sensitivity Testing for Plasmodium falciparum and
Plasmodium vivax. J. Dent. Med. Sci., 14(4): 49-55. DOI: http://dx.doi.org/10.9790/085314464955.

Trager W, Jensen JB. 1976. Human Malaria Parasites in Continuous Culture.

Sci., 193(4254): 673-675. DOI: http://dx.doi.org/10.1126/science.781840 Umar AY, Nasir AI, Aliyu MM, Dangana A, Vanstawa PA. 2017. In-Vitro Antimalarial Resistance Pattern of Plasmodium Falciparum Infection among Pregnant Women in Northern Nigeria. Afro-Egypt J. Infect. Endem. Dis., 7(2): 47-51.

Wande OM, Babatunde SB. 2018. In vitro screening of ten Combretaceae plants for antimalarial activities applying the inhibition of beta-hematin formation. Int. J. Biol. Chem. Sci., 11(6): 2971. DOI: http://dx.doi.org/10.4314/ijbcs.v11i6.33.

World Health Organization. 2001. In vitro micro test (Mark III) for assessment of the response of Plasmodium falciparum to chloroquine, mefloquine, quinine, amodiaquine, sulfadioxine/pyrimethamine, and artemisinin. CTD/ MAL/97.20, World Health Organization.

World Health Organization. 2014. World Malaria Report. World Health Organization, Geneva, Switzerland.

World Health Organization. 2016. World Malaria Report. World Health Organization, Geneva. Switzerland.

World Health Organization. 2018. World Malaria Report. World Health Organization. WHO Press: Geneva, Switzerland. 